\title{
Methodology supporting production control in a foundry applying modern DISAMATIC molding line
}

\author{
Robert Sika ${ }^{1, *}$, and Pawet Popielarski ${ }^{1}$ \\ ${ }^{1}$ Poznan University of Technology, Institute of Material Technology, Piotrowo 3 Street, Poland
}

\begin{abstract}
The paper presents methodology of production control using statistical methods in foundry conditions, using the automatic DISAMATIC molding line. The authors were inspired by many years of experience in implementing IT tools for foundries. The authors noticed that there is a lack of basic IT tools dedicated to specific casting processes, that would greatly facilitate their oversight and thus improve the quality of manufactured products. More and more systems are installed in the ERP or CAx area, but they integrate processes only partially, mainly in the area of technology design and business management from finance and control. Monitoring of foundry processes can generate a large amount of processrelated data. This is particularly noticeable in automated processes. An example is the modern DISAMATIC molding line, which integrates several casting processes, such as mold preparation, assembly, pouring or shake out. The authors proposed a methodology that supports the control of the above-mentioned foundry processes using statistical methods. Such an approach can be successfully used, for example, during periodic external audits. The mentioned methodology in the innovative DISAMProdC computer tool was implemented.
\end{abstract}

\section{Introduction}

In times of modern globalization and development of commerce, followed by a need of fulfilling more and more restrictive conditions of acceptance by a client, almost any significant manufacturing company must automate its production processes [1]. Modern and specialized machines and devices, installed widely, are usually sold together with a dedicated computer software. With a help of measurement devices, they are responsible for monitoring of the production processes, supplying a user with necessary information about a process state, to control it [2]. In the era of the "Industry 4.0" concept gaining more and more popularity, there is an assumption of a close relation between an industrial revolution, automation and data processing, but also with consideration of notions such as the cyber-physical systems [3] or Virtual Reality [4]. The companies are therefore equipped with proper tools to manufacture and supply products and services of high quality, maximally adjusted to needs and expectations of clients. On the other hand, technical and organizational aspects of company operation is also important, meaning

* Corresponding author: robert.sika@put.poznan.pl 
supplying products in an acceptable time, shortening of production cycle, limiting of wastage and costs of production [5]. It is possible not only thanks to application of modern production devices, but also due to reasonable use of verified methods and tools (including the statistical ones) for aiding the decision making in the field of manufacturing, its organization and control [6].

Manufacturing processes in the foundry industry are among the most complex ones and automation is particularly observable in this industry in recent years [7]. This is mostly a result of process and organizational complexity of casting production. It results directly of diversification of materials used for casting production, but also out of course and relations between different stages of partial processes $[8,9]$. The foundry processes, especially the fully automated ones, usually generate high amount of data related to course of processes. As an example, modern molding lines of DISAMATIC type, more and more frequently installed in foundries in the last two decades, are a good example here. They can integrate even several processes, such as mold preparation, its assembly, pouring, knocking out a casting, cooling and shot-blasting. Unfortunately, there is a problem with the mentioned amount of generated data assigned to particular parameters, often not much useful for on-going production control. Depending on a type of installed molding line, even several hundred parameters can be generated, while most of them are useful only to employees of maintenance departments.

The authors have proposed a new methodology, which aids control of foundry processes related to the DISAMATIC molding line, with use of statistical methods. Such an approach may be applied not only for the current production control, but also, for example, during periodical external audits, when it is important to show influence of specific parameters on final casting quality.

\section{DISAMATIC Automatic Molding Lines}

The Automatic Molding Lines (AML) have gained certain popularity in foundry for a few important reasons. They are the obtained processing effect, the level of efficiency and reliability of molding above $98 \%$ [10]. The process of automatic forming allows obtaining of a very high quality of a mold, of uniform and high degree of densification of the mold sand, as well as high dimensional accuracy. Prevalence of AML use in processes of casting manufacturing is also a result of economics of the molding process. Ratio of quality of an obtained mold and efficiency of the process to costs of manufacturing of molds is very beneficial, especially in the case of DISAMATIC working lines [11].

Development of AML is related to a continuous improvement in field of mechanization and automation. Modern solutions of building molding lines concentrate mostly on processes of automated control, diagnosis and operation with use of robots and manipulators. Adjustment of processes is based on an on-going control of casting processes [12]. Current development of AML strives towards building flexible structures, based on modular construction, what corresponds to needs of quick re-arming of a production line. Here it must be mentioned, that by the end of XX. century many foundries still used molding lines, where processes of core manufacturing, mold pouring and knocking out of castings were realized outside an automated cycle. New generations of automated molding lines concern full automation of many activities related to casting making [13]. Such lines, fully automated, commonly use microprocessors for control, diagnosis and data recording. In the solutions proposed nowadays, visualization systems are used for imaging of current course of casting processes, as well as for their control and adjustment [11-13].

Despite such an advancement, tremendous amount of recorded data may be overwhelming and - as results of authors' experience - usually is not useful for on-going control of casting processes. It is particularly visible in case of work of quality control departments, where it is obvious to look for reasons behind the most frequent defective products. 


\section{New concept of production control for the DISAMATIC lines}

\subsection{Research preparation. Data acquisition}

The studies were conducted in an European foundry, producing cast iron castings, of mass between few and few dozen kilograms, mostly for automotive and machine construction industry. Major part of the casting production is carried out on an automated molding line of DISAMATIC 230 type, with vertical mold division. For the studies, core castings manufactured using this line were selected, of mass of approx. $20 \mathrm{~kg}$. As the production is for the automotive industry, a client often personally receives and accepts a batch of castings, according to guidelines by a branch standard ISO-TS16949 [14].

The authors proposed a juxtaposition of the most significant process parameters, recorded on the DISAMATIC line and outside it. The parameters were selected by their influence on a most frequently occurring defect in a series (approx. 140 pieces of poured molds, 2 castings in a mold), which is shrinkage. As results of gathered literature $[15,16]$ this defect is frequently noted as a leading one in case of manufacturing castings using AML. The mentioned parameters were assigned to topography of data sources by the authors (Fig. 1).

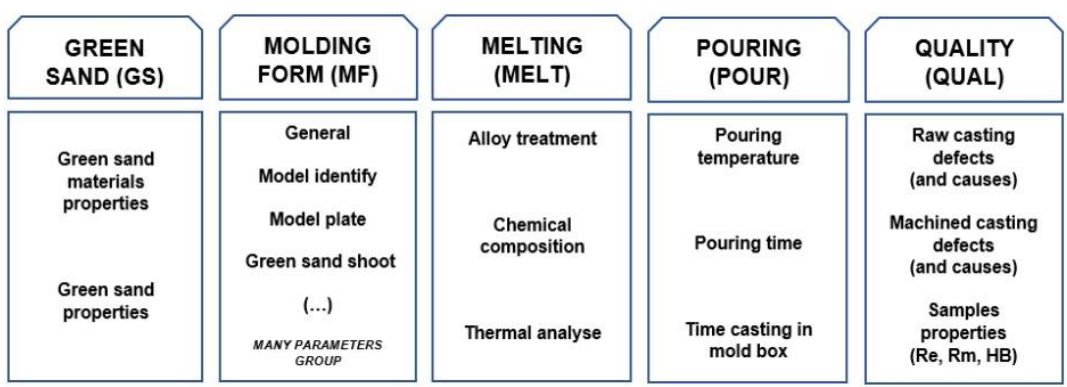

Fig. 1. Topography of data sources in the investigated foundry - simplified schema.

The most important parameters, in authors' opinion, related to a phenomenon of shrinkage defect forming, were put together (see Table 1). The parameters were divided into 3 groups:

- G1 - parameters recorded by the DISAMATIC modules (automated measurements),

- G2 - parameters recorded outside the DISAMATIC line (automated and semi-automated measurements),

- G3 - parameters recorded by a worker (manual measurements).

Table 1. Summary of parameters collected in the foundry (chosen data sources).

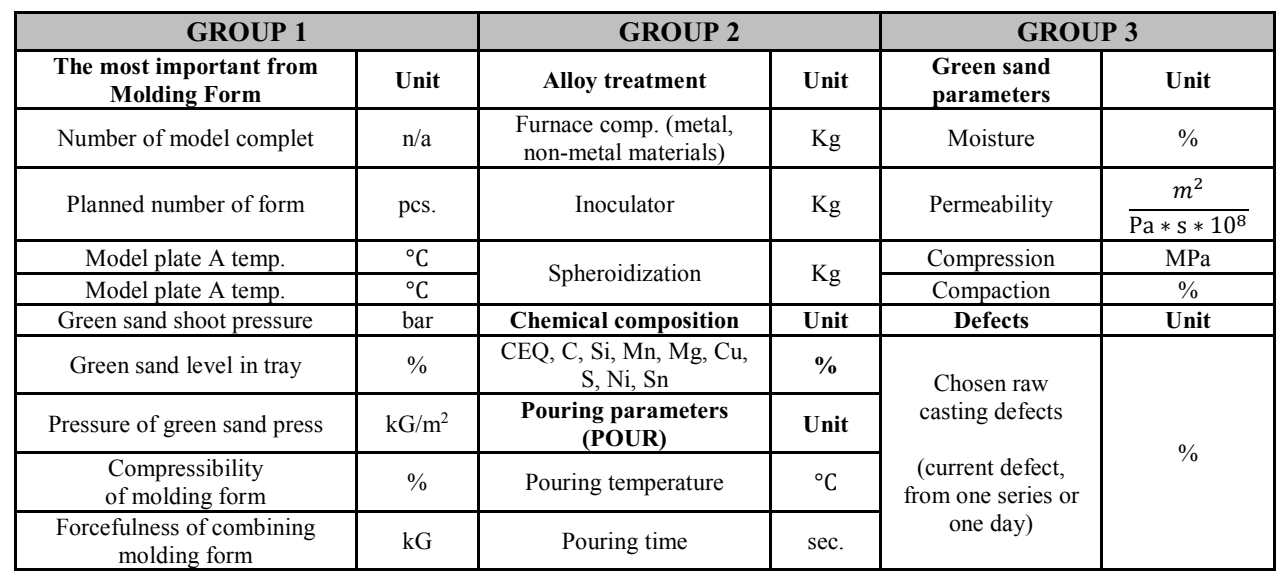


Group 2 contains parameters recorded by measurement devices not directly coupled with the electronic control system of the molding line (automated measurements or semiautomated measurements with partial engagement of a human operator). Both group 2 and 3 contain very important parameters, that were not recorded by the DISAMATIC device at the time of conducting the studies by the authors.

\subsection{Development of a methodology of production control for the DISAMATIC molding line}

As mentioned in chapter 2, amount of data collected in automated foundries is very high. First of all, it should be limited to the most relevant parameters, which directly influence a phenomenon of forming of a specific defect. Frequency of gathering these parameters is also different. It is therefore necessary to assume, that juxtaposition of parameters on one time axis will require certain approximation of time relations between them, regarding a specific poured mold or series. However, in practice, such a full synchronization is not possible in each real case and it must be based upon certain averaging of values of the most frequently recorded parameters. It is therefore important to assume one parameter with a leading timeline (a reference time), to which all the other parameters will be associated. Usually it is a process being the most close to shaping a casting, meaning the process of mold pouring (a moment of pouring).

A solution proposed by the authors is a methodology, which consists in use of parameters coming from the DISAMATIC (GROUP 1) and outside this molding line (GROUP 2 and GROUP 3). The authors propose to select only certain parameters in scope of the first group. The parameters should be related mostly to process of mold preparation at a stage of its shaping with use of modelling plates and mold completing (assembling two half-molds, which eventually create a mold ready for casting). The presented methodology of production control assumes selection of parameters and efficient evaluation of their influence on final quality of castings in a foundry, which applies the DISAMATIC automation. A concept scheme of proceeding is shown in Figure 2.

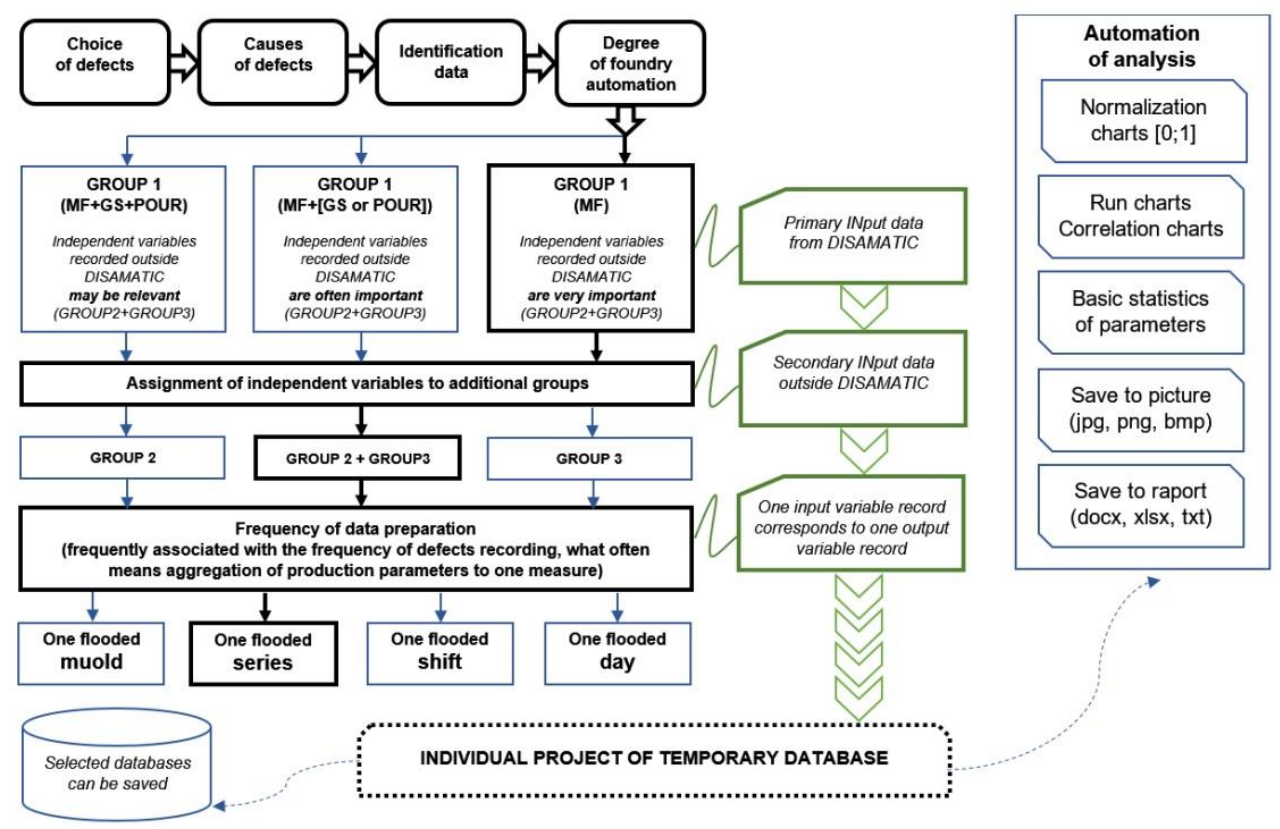

Fig. 2. Scheme of production control methodology for the DISAMATIC molding line. 


\subsection{Project of the DISAM-ProdC computer system}

This section shortly presents the DISAM-ProdC (DISAMATIC Production Control) application. Its task is automation of activities described in the production control methodology. Two modules were proposed in the test phase: "automation of data acquisition" and "automation of analyses".

In the first case, the application generates a new database, on the basis of defined search criteria. The prepared database is analyzed in the "automation of analyses" module. Most of all, it was assumed to have a possibility of studying influence of one or several independent variables on a defect (dependent variable), presented to an employee in a clear and readable way. Figure 3 presents an exemplary screenshot of the "automation of data acquisition" module, while Figure 4 presents exemplary results of analyses - influence of selected parameters on the shrinkage type defect. In this case, the authors applied data scaling to a range between " 0 " and " 1 ", where the first negative value means a minimal value of a set of a specific parameter, while a positive value means a maximal value of this set. An aim is to illustrate a graphical change of values of these parameters, in relation to percentage share of the defect (from 18.10.2016 to 21.10.2016 for each series per day: S1, S2 ...etc.). The real value is shown after clicking on a specific data point in a diagram with a mouse button (see "ID point" in Fig.4).

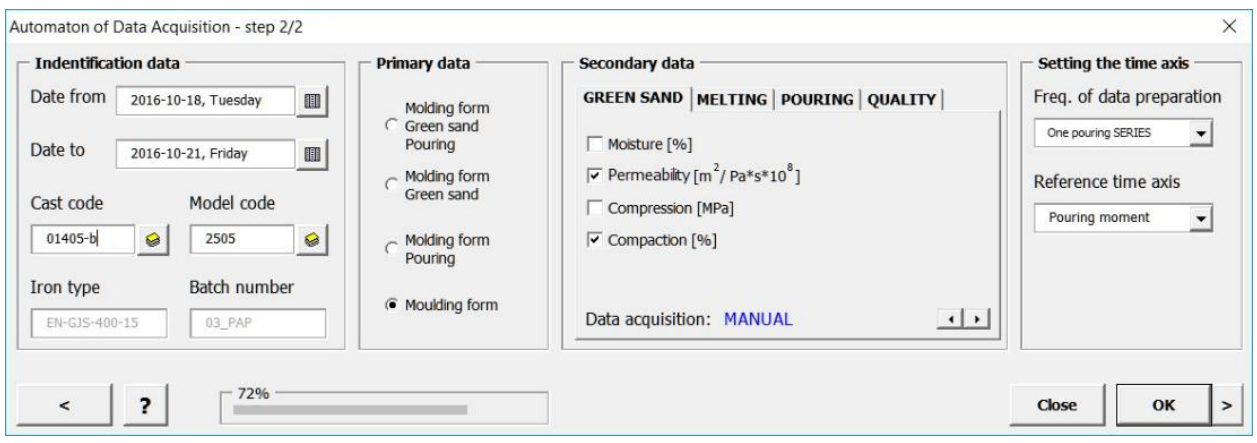

Fig. 3. The "Automation of Data Acquisition" module.

NORMALIZATION CHART from 18.10.2016 to 21.10.2016 (for pouring series) INput data (dashed line) [/] and OUTput data (Shrinkage) [\%]

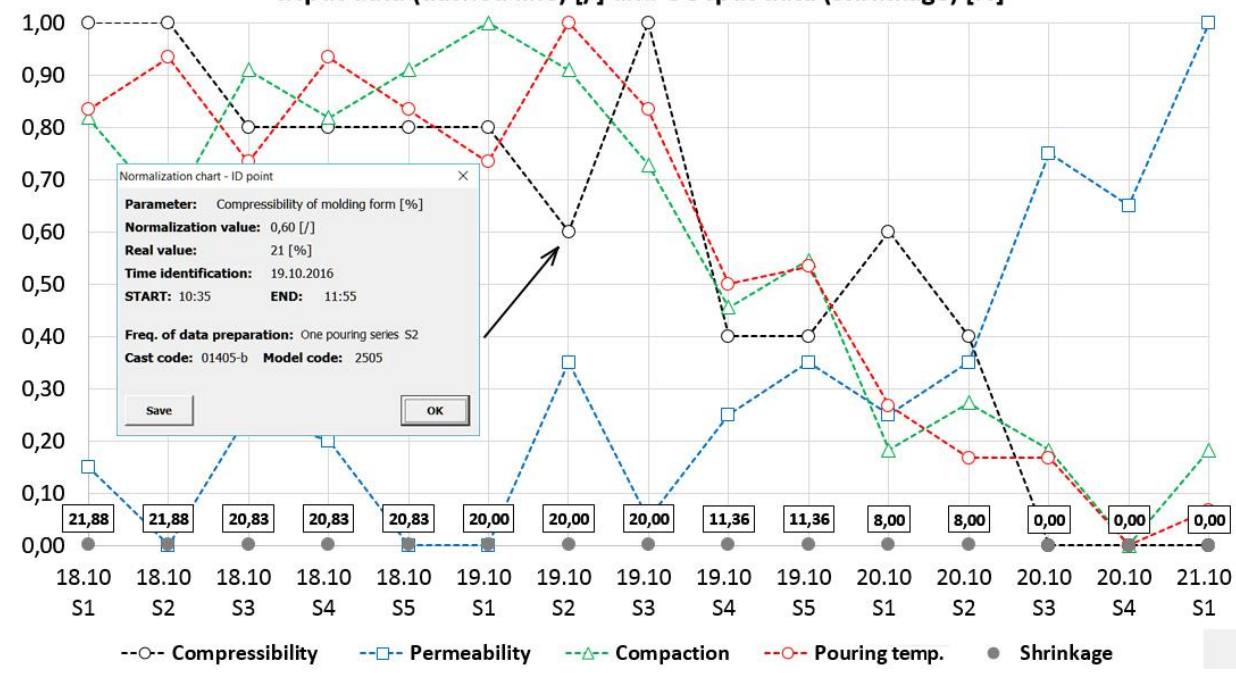

Fig. 4. The "Automation of Analyses" module. 


\section{Summary}

The paper presents authors' own approach to production control in an automated foundry using a modern forming line DISAMATIC. The foundry is an example of a production system, where integration of many production processes responsible for receival of a final product (a casting) is visible. In these companies, modern machines and devices for work automation are installed more and more often and this contributes to generation of a huge amount of data, out of which not all are useful for the on-going production control.

The authors have proposed a modern methodology, that, by assumption, supports control of production processes with use of statistical methods. Above all, optimal selection of independent variables was assumed, considering a criterion of efficient conducting of basic statistical analyses.

The methodology was implemented in authors' own program DISAM-ProdC. It must be emphasized, that for the employees of the foundry, it is particularly important to perform quick analyses in a simple way. Excess functions, parameters and preliminary settings in computer programs aiding the production control may only discourage using them. Aim of the authors was, most of all, showing that among many independent variables, the most important ones can be selected to present their influence on final quality of castings, in form of simple analyses and statistic sheets. As results of authors' experience, such quick and practical analyses are very often useful for quality controllers, aiding current control of casting quality.

\section{References}

1. D. Schütz, A. Wannagat, C. Legat, IEEE Trans. On Ind., 9(4), 2397, (2013)

2. K. J. Aström, B. Wiitenmark, Adaptative Control. Second Edition, (Lund Intitute of Technology, Mineola, New York, 2013)

3. J. Lee, B. Bagheri, H. Kao, Man. Lett., Elsevier, 3, 18 (2015)

4. F. Górski, R. Wichniarek, P. Zawadzki, P. Buń, A. Hamrol, Proc. Comp. Sc., 75, 137 (2015)

5. M.R.L. Varela, J. Trojanowska, S. Carmo-Silva, N.M.L. Costa, J. Machado, Manag. and Prod. Eng. Rev., 8(2), 69 (2017)

6. A. Kujawińska, R. Rogalewicz, M. Diering, A.Hamrol, WorldCIST, Adv. in Int. Sys. and Comp., Springer, 571, 499 (2017)

7. Z. Ignaszak, R. Sika, M. Perzyk, A. Kochański, J. Kozłowski, Arch. Of Found. Eng., 16(1), 5 (2016)

8. S. Saalem, M. Malik, S. Gottschling, J. Hartman, Proc. 71st World Foun. Cong. (WFC), Bilbao, Spain. 1 (2016)

9. T.R. Vijayaram, S. Sulajman, A.M.S. Hamouda, M.H.M Ahmad, J. of Mat. Proc. Techn., 178 (2006)

10. R. Banchhor, S. K. Ganguly, Proceedings in: Interational Journal of Advanced Engineering Research and Studies, 4, 227 (2015)

11. M. Colditz, S.K. Kang, H.S. Kim, P. Larsen, Found. Trad. J. Int. (2015)

12. *** DISA, A Norican Technology, Moulding Solution, https://www.disagroup.com/ (2017)

13. J. Dańko, A. Fedoryszyn, Sold. Of Metals And Alloys, 1(41), 34

14. ISO/TS 16949, Automotive Quality Management, (2009)

15. I. Hahn, J. C. Sturm, Proceedings of the 69th World Foundry Congress, (2010)

16. M. Sutaria, D. Joshi, M. Jagdishwar, B. Ravi, Trans. Amer. Found. Soc., 119 (2011) 